\title{
Research Article \\ Effects of Interfacial Charge on the DC Dielectric Properties of Nanocomposites
}

\author{
Jiaming Yang, Congji Liu, Changji Zheng, Hong Zhao, Xuan Wang, and Mingze Gao \\ Key Lab of Engineering Dielectrics and Their Application, Ministry of Education, Harbin University of Science and Technology, \\ Harbin 150080, China \\ Correspondence should be addressed to Jiaming Yang; yang_jiaming@163.com
}

Received 5 January 2016; Revised 27 January 2016; Accepted 1 February 2016

Academic Editor: Christian Brosseau

Copyright (C) 2016 Jiaming Yang et al. This is an open access article distributed under the Creative Commons Attribution License, which permits unrestricted use, distribution, and reproduction in any medium, provided the original work is properly cited.

\begin{abstract}
The interfacial charge phenomenon of $\mathrm{MgO} /$ low-density polyethylene (LDPE) and $\mathrm{SiO}_{2} / \mathrm{LDPE}$ nanocomposites was measured by synchrotron radiation small-angle X-ray scattering. Based on the Porod theory, the Porod curve of $\mathrm{SiO}_{2} / \mathrm{LDPE}$ nanocomposite shows negative divergence but the LDPE and MgO/LDPE do not, which reveals that interfacial charge may exist in the $\mathrm{SiO}_{2} / \mathrm{LDPE}$ nanocomposite. The DC dielectric properties of the nanocomposites are closely related to the interfacial charge. Experimental results show that the $\mathrm{SiO}_{2} / \mathrm{LDPE}$ nanocomposite has lower DC conductivity, less space charge, and higher DC breakdown strength than the $\mathrm{MgO} / \mathrm{LDPE}$ nanocomposite. It is thought that the interfacial charge has a positive effect on the DC dielectric performance of nanocomposites, and the mechanism could be attributed to the scattering effects of the interfacial charge on the carrier migration. There is no obvious interfacial charge in the $\mathrm{MgO} / \mathrm{LDPE}$ nanocomposite, but it still has excellent $\mathrm{DC}$ dielectric properties compared with LDPE, which indicates that the interfacial charge is not the only factor affecting the dielectric properties; the dipole interface layer and the reduction of free volume can also inhibit the migration of carriers and decrease electrons free path, improving the dielectric performance.
\end{abstract}

\section{Introduction}

Nanocomposites with improved dielectric properties have recently received much attention [1-5]. Japanese researchers reported that adding a small amount of nano-MgO powder to low-density polyethylene (LDPE) can effectively decrease the amount of space charge in the material [6]. Nelson demonstrated that $\mathrm{SiO}_{2}$ /cross-linked polyethylene (XLPE) showed larger DC breakdown strength at $90^{\circ} \mathrm{C}$ relative to unfilled XLPE [7]. Polymer nanocomposites are structured in the form of a polymer matrix with several weight percentages of nanoparticles on the scale of less than $100 \mathrm{~nm}$ homogeneously dispersed. Because nanosized fillers with large specific surface area may form large interfacial zones in the nanocomposite, it is supposed that the interface may be the key and dominate the electrical properties of the nanocomposite.

The change in the electrical properties of nanocomposites was explored by Lewis, wherein the interfacial charge may dominate the eventual dielectric performance [8]. Accordingly, Tanaka et al. predicted that charge transfer may occur between inorganic nanoparticles and the organic polymer matrix because of their different physical and chemical properties [9]. Lewis and Tanaka's interface model distinguishes two layers present when charge transfer occurs. The first layer, called the Stern layer, with a thickness of $1 \mathrm{~nm}$, consists of countercharges absorbed on the surface of nanoparticles. The second layer, the Gouy-Chapman double layer, with a thickness of approximately $100 \mathrm{~nm}$, consists of mobile positive and negative ionic charges attracted or repulsed by any net charge in the nanoparticle system and the first layer. The common view of the two scholars is that an interfacial charge layer may exist in the nanocomposite.

Although many experimental results have been obtained and some models for nanocomposites have been proposed, the mechanism responsible for the significant dielectric improvement in nanocomposites is still not very clear. 
First, if the interfacial charge has the dominant effect on the dielectric properties of nanocomposites, does it really exist in $\mathrm{MgO} / \mathrm{LDPE}$ or $\mathrm{SiO}_{2} / \mathrm{LDPE}$, whose dielectric properties were improved? There are some detection methods that could demonstrate the charge layer illustrated by Lewis and Tanaka. Second, various nanopowders, such as $\mathrm{MgO}$ or $\mathrm{SiO}_{2}$, have different physical and chemical properties; will these differences influence the charge layer and the subsequent dielectric performance of nanocomposites? Figuring out these problems will be of great importance in preparing nanocomposites capable of significantly improved dielectric properties.

Synchrotron radiation small-angle X-ray scattering (SAXS), where the scattering angle is less than $5^{\circ}$, is a coherent scattering phenomenon. When nanoscale inorganic particles are dispersed in the base materials, by measuring the variation of electron density at the interface, the structure and morphology of the interface can be demonstrated by SAXS [10]. According to the Porod law, inorganic nanoparticles and hydrocarbons such as LDPE have different atomic numbers and electron densities. When the interface between the two phases is sharp, the two phases have a uniform electron density, so the Porod curve should show no deviation. However, if the interface between the two phases is diffusive, as in Lewis's model, there is a diffused charge layer in the interface and the Porod curve will show a negative divergence.

Liu et al. investigated the interfacial situation in $\mathrm{PI} / \mathrm{Al}_{2} \mathrm{O}_{3}$ films using small-angle X-ray scattering (SAXS) with synchrotron radiation as an X-ray source [11]. The results indicated that the scattering curves in the high-angle region have a negative slope, which suggests that there are obvious interface layers between the organic phase and the inorganic phase in the PI films. Yao et al. tested the interfacial properties of a silicon dioxide sol using SAXS and found that the interfacial state may result in negative deviation from Porod's law [12].

In this paper, based on the model of the interfacial charge layer explored by Lewis, we attempted to measure the interfacial charge phenomenon of $\mathrm{MgO} / \mathrm{LDPE}$ and $\mathrm{SiO}_{2} / \mathrm{LDPE}$ nanocomposites using SAXS and then to determine the relationship between the dielectric properties and interfacial charge properties of $\mathrm{MgO} / \mathrm{LDPE}$ and $\mathrm{SiO}_{2} / \mathrm{LDPE}$.

\section{Materials and Methods}

2.1. Preparation of Samples. LDPE was obtained from BASFYPC Co., Ltd. Nano-sized $\mathrm{MgO}$ and $\mathrm{SiO}_{2}$ powders with average diameters of $20 \mathrm{~nm}$ were acquired from Nanjing Haitai Nano Material Co., Ltd., China. The nanopowders were packed in an aluminum foil bag to prevent them from getting damp in the process of storage. The initially polar, hydrophilic surfaces of nano- $\mathrm{MgO}$ and $\mathrm{SiO}_{2}$ were modified to be nonpolar and hydrophobic with aminopropyltrimethoxysilane.

Nanoparticles modified by silane coupling were blended with LDPE, with mass fractions of $2 \%-20 \%$. Samples were then hot-pressed into squares with thicknesses of $0.1 \mathrm{~mm}$, $0.2 \mathrm{~mm}$, or $0.3 \mathrm{~mm}$. The samples with thicknesses of $0.1 \mathrm{~mm}$ were used in the SAXS test. The samples used in dielectric tests were two vaporized $\mathrm{Al}$ electrodes. For DC conduction tests, $\mathrm{Al}$ electrode $76 \mathrm{~mm}$ in diameter was vaporized as the high-voltage electrode, $\mathrm{Al}$ electrode $54 \mathrm{~mm}$ in inner diameter and $74 \mathrm{~mm}$ in outer diameter was used as the guarding electrode, and $\mathrm{Al}$ electrode $50 \mathrm{~mm}$ in diameter was used as the measuring electrode. For space charge and electrical breakdown tests, two $\mathrm{Sl}$ electrodes $35 \mathrm{~mm}$ in diameter were vaporized. All samples were conditioned before each measurement (i.e., heated at a chamber pressure of $1 \times 10^{-2}$ Torr, for $48 \mathrm{~h}$ under a short-circuited condition, at a temperature of $80^{\circ} \mathrm{C}$ ) to allow drying and remove volatile contents.

2.2. Measurement of SEM. Samples were hot-pressed into squares with thicknesses of $1 \mathrm{~mm}$ and then fractured by liquid nitrogen cooling. The fractured surface was not coated with gold because the diameters of gold particles and inorganic nanoparticles were very similar, which may interfere with the observation results. Because the fractured surface was not conductive, the scanning electron microscopy must work at low accelerating voltage mode to reduce the amount of charge accumulation on the surface of the samples. A Hitachi highresolution scanning electron microscope (SU8020), which can operate at an accelerating voltage of $1.0 \mathrm{kV}$, was selected to observe the dispersion of nanoparticles in the nanocomposites.

2.3. Measurement of SAXS. SAXS experiments were carried out at the Institute of High Energy Physics of the Chinese Academy of Sciences. The photon energy ranged from 4 to $14 \mathrm{keV}$, and the wavelength of the X-rays was approximately $0.154 \mathrm{~nm}$. The resolution of the imaging plate detector is $100 \mu \mathrm{m}$.

2.4. Measurement of FTIR. Fourier Transform Infrared spectra were obtained by Jasco FTIR-6100 in the range from 400 to $5000 \mathrm{~cm}^{-1}$. Nanoparticles were uniformly mixed with $\mathrm{KBr}$ powder and then compressed into films, which were tested by using transmission mode. The background of the atmosphere was measured and subtracted from each spectrum.

2.5. Measurement of XRD. The X-ray diffraction (XRD) patterns of the $\mathrm{MgO} / \mathrm{LDPE}$ and $\mathrm{SiO}_{2} / \mathrm{LDPE}$ thin films were investigated by X-ray diffraction on Philips X'Pert X-ray diffractometer in the range from $10^{\circ}$ to $100^{\circ}$.

2.6. Measurement of Conductivity. Quasi-steady state current was measured by Keithley 6517A. In the relationship between conductivity and electric field, points at different electric field at $70^{\circ} \mathrm{C}$ were chosen, and the sampling time at each point was $30 \mathrm{~min}$. The final result was obtained by averaging the test results of four samples.

2.7. Measurement of Space Charge. Space charge properties were measured by the electroacoustic pulse method. The PEA system is produced by Shang Hai Xiangtie Electromechanical Device Co., Ltd., China. We measured the space charge distribution of our nanocomposite following $40 \mathrm{kV} / \mathrm{mm}$ polarization for $30 \mathrm{~min}$ under DC field. To verify the repeatability of experimental results, we measured the space charge distribution three times. 


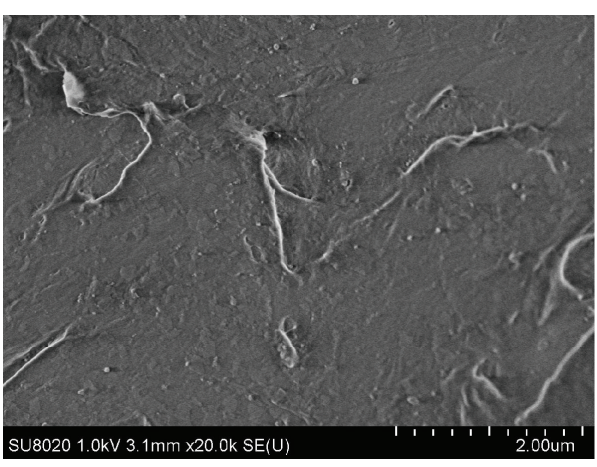

(a)

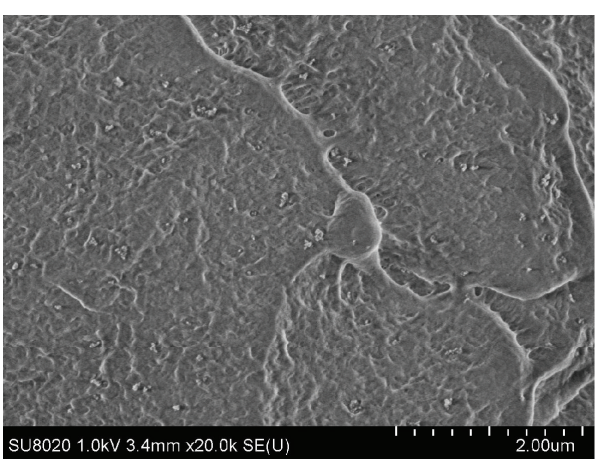

(c)

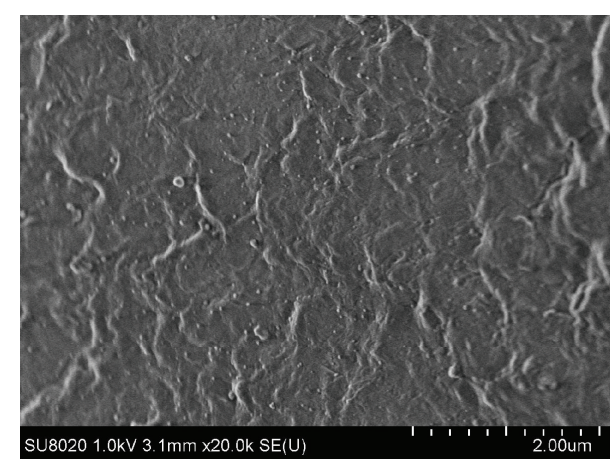

(b)

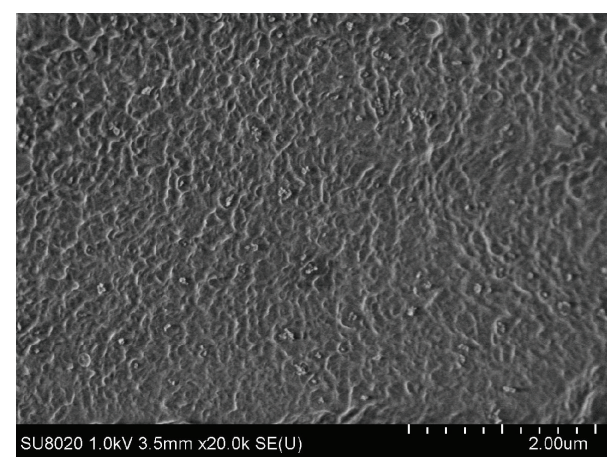

(d)

FIGURE 1: SEM photographs of the dispersion of nanoparticles in nanocomposites. (a) $2 \mathrm{wt} \% \mathrm{MgO} / \mathrm{LDPE}$. (b) $3 \mathrm{wt} \% \mathrm{MgO} / \mathrm{LDPE}$. (c) $2 \mathrm{wt} \%$ $\mathrm{SiO}_{2} /$ LDPE. (d) $3 \mathrm{wt} \% \mathrm{SiO}_{2} /$ LDPE.

2.8. Measurement of Breakdown Strength. The breakdown strength data of solid insulation materials are usually variable, so the probability distribution was calculated by the twoparameter Weibull distribution, which can be written as

$$
P(E)=1-\exp \left[-\left(\frac{E}{E_{0}}\right)^{\beta}\right],
$$

where $E$ is the measured electric field strength at breakdown and the data are variable and $E_{0}$ is the scale parameter, the breakdown field for a probability of $0.632 . \beta$ is the shape parameter, related to the scatter of the breakdown data.

\section{Results}

3.1. SEM. Figure 1 shows the dispersion of nanoparticles in the $\mathrm{MgO} / \mathrm{LDPE}$ and $\mathrm{SiO}_{2} / \mathrm{LDPE}$ nanocomposite. Because the fractured surface was not coated with gold, the accelerating voltage was set at $1 \mathrm{kV}$ to reduce the amount of charge accumulation on the surface of the samples. It can be seen that nanoparticles were homogeneously dispersed and the size of most nanoparticles was less than $100 \mathrm{~nm}$.

3.2. Interface Charge. The scattering intensity of any system is given by [12]:

$$
\begin{aligned}
I(q) & =I_{e}\left\langle(\Delta \rho)^{2}\right\rangle \times V \int_{0}^{\infty} \gamma(r) \sin (q r) 4 \pi r^{2} d r \\
q & =\frac{4 \pi \sin \theta}{\lambda}
\end{aligned}
$$

where $q$ is the scattering vector; $\theta$ is half of the scattering angle; $\lambda$ is the incident X-ray wavelength; $I_{e}$ is the scattering intensity of a single electron; $V$ is the $\mathrm{X}$-ray irradiation volume; $\gamma(r)$ is a function describing the spatial electron density fluctuation; and $\left\langle(\Delta \rho)^{2}\right\rangle$ is the mean square of space electron density fluctuations in the system of particles and matrix.

According to Porod's law, an ideal two-phase system with a sharp interface, under the condition of long slit collimation, with a curve $\left[\ln \left(q^{3} I(q)\right)\right]-q^{2}$ in large scattering angles, tends to be a straight line [14]; namely,

$$
\lim _{q \rightarrow \infty}\left[q^{3} I(q)\right]=K
$$

where $K$ is the Porod constant.

When the interface of the two phases is diffusive, Porod curve $\left[\ln \left(q^{3} I(q)\right)\right]-q^{2}$ will show negative divergence; namely,

$$
\begin{aligned}
\ln \left(q^{3} I(q)\right) & =\ln K-\sigma^{2} q^{2}, \\
D^{2} & =2 \pi \sigma^{2},
\end{aligned}
$$

where $\sigma$ is the thickness parameter and $D$ is the thickness of the interface layer.

Porod's curves for $\mathrm{MgO} / \mathrm{LDPE}$ and $\mathrm{SiO}_{2} / \mathrm{LDPE}$ nanocomposite films with various contents are shown in Figure 2. According to Porod's law, the interfacial property is primarily characterized by a negative deviation of the Porod curve when $q^{2}$ value is large. In this paper, we focus on the Porod curves, 


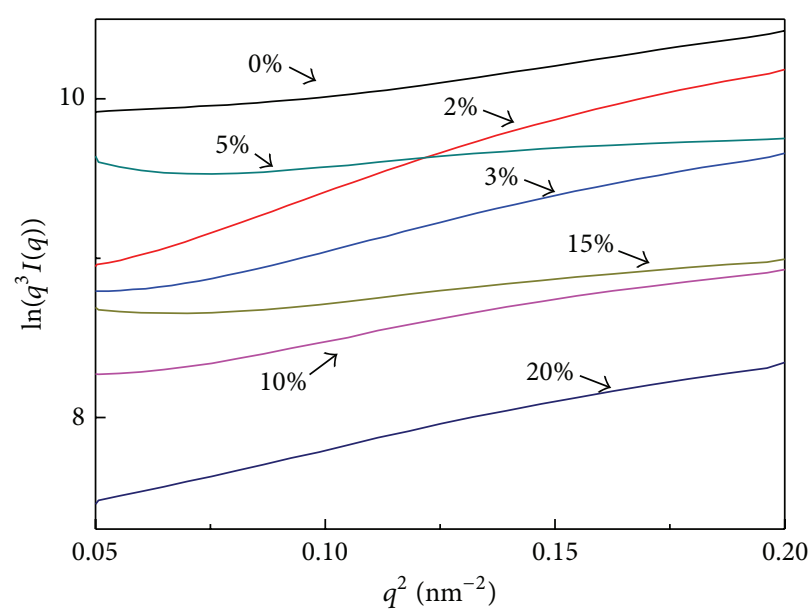

(a)

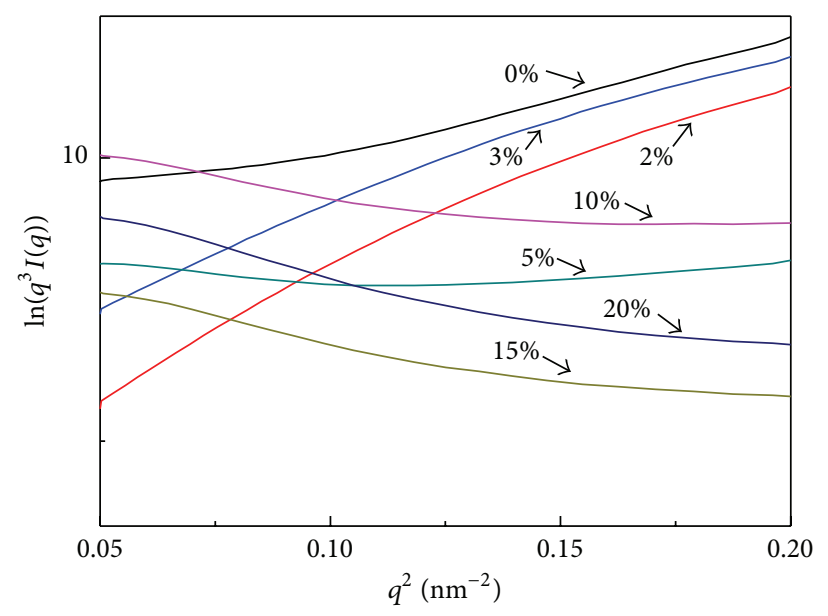

(b)

Figure 2: Porod curve of different nanocomposites. (a) MgO/LDPE. (b) $\mathrm{SiO}_{2} / \mathrm{LDPE}$.

which deviate from the law when $q^{2}$ value is greater than $0.1 \mathrm{~nm}^{-2}$.

It can be seen from Figure 2(a) that the slope of the Porod curve shows positive divergence for pure LDPE. Previous research has shown that an amorphous region may cause the Porod curve to have a positive divergence [15]. The crystallinity of LDPE is less than $50 \%$. This may be the reason for the deviation of the Porod curve. By adding nano-MgO powders to LDPE, we find that the Porod curve still shows a positive divergence.

Different from $\mathrm{MgO} / \mathrm{LDPE}$, as shown in Figure 2(b), when the filling weights of nano- $\mathrm{SiO}_{2}$ powders were less than $10 \%$, the Porod curve presented a positive deviation. However, when the filling weights of nano- $\mathrm{SiO}_{2}$ powders reached $10 \%$, the $\mathrm{SiO}_{2} / \mathrm{LDPE}$ Porod curve presented an obvious negative deviation.

The SEM images presented in Figure 1 suggest that $\mathrm{SiO}_{2}$ is more agglomerated (even at low content) than $\mathrm{MgO}$ in the respective nanocomposites and the Porod curves presented in Figure 2 indicate a negative divergence at loadings above $10 \mathrm{wt} \%$ for $\mathrm{SiO}_{2} / \mathrm{LDPE}$ but not for MgO/LDPE nanocomposite. This begs the question of whether particle size is likely to influence the Porod curve. Indeed, the particle size distribution will interfere $I(q)$ curve, but the interference degree is decreasing as $q$ value is increasing. In the range we focus on, the interference is very weak. Based on the Porod theory, when $q$ value is large, whatever the particle size is, $q^{3} \ln (q)$ will tend to a certain value; if the relation of $\left[\ln \left(q^{3} I(q)\right)\right]$ and $\ln K$ presents negative deviation it means that the interface layer exists.

In our previous research, using an electrostatic force microscope, the charge distribution around nanoparticles in nanocomposites was detected [13]. An interface charge was found in $\mathrm{SiO}_{2} / \mathrm{LDPE}$ nanocomposites, but not in $\mathrm{MgO} / \mathrm{LDPE}$ nanocomposites. Differences between the electrostatic force microscope lift mode phase images of the MgO/LDPE and $\mathrm{SiO}_{2} /$ LDPE samples' surfaces are shown in Figures 3(c) and 3(d). The visible dark areas, which demonstrate the charge zones, only appear in $\mathrm{SiO}_{2} / \mathrm{LDPE}$, as shown in Figure 3(d), and do not appear in $\mathrm{MgO} / \mathrm{LDPE}$, as shown in Figure 3(c). The filling weights of nanopowders are $2 \%$, and the materials are the same as we used in this paper. However, we could only detect the interfacial charge in $\mathrm{SiO}_{2} / \mathrm{LDPE}$ when the loading weights of nano- $\mathrm{SiO}_{2}$ powders were greater than $10 \%$ in the SAXS test.

As the filling amounts of nanopowders increased, the volume of the interface zone in nanocomposites also increased and the distance between different interface layers decreased. This means that, under the same irradiation volume, higher filling amounts lead to weaker scattering by the interface layers, which leads to a Porod curve that presents an obvious negative deviation. When the filling amounts are low, although the interface charge layer also exists, the volume fraction of the interface layers is relatively small in a certain volume of irradiation, so a negative deviation of the Porod curve is not observed.

From the SAXS result mentioned above, we found that the Porod curve of $\mathrm{SiO}_{2} / \mathrm{LDPE}$ with higher loading weights showed different characteristics compared with LDPE and the $\mathrm{MgO} / \mathrm{LDPE}$ nanocomposite. The negative deviation of Porod curves for the $\mathrm{SiO}_{2} / \mathrm{LDPE}$ nanocomposite could be attributed to the interfacial charge layer in $\mathrm{SiO}_{2} / \mathrm{LDPE}$. The SAXS and electrostatic force microscope results for $\mathrm{SiO}_{2} / \mathrm{LDPE}$ are in good agreement.

3.3. DC Conductivity. Figure 4 shows the conductivity versus electric field characteristics of three kinds of materials at $70^{\circ} \mathrm{C}$. As shown in Figure 3, the conductivities of MgO/LDPE and $\mathrm{SiO}_{2} / \mathrm{LDPE}$ nanocomposites are significantly lower than that of LDPE, and the conductivity of $\mathrm{SiO}_{2} / \mathrm{LDPE}$ is the lowest among the three kinds of materials.

The conductivity of a dielectric is closely related to the concentration and mobility of carriers. For nanocomposites, because the filling powders had a high degree of purity, the concentrations of carriers in LDPE and nanocomposite could be considered approximately the same. Therefore, the 


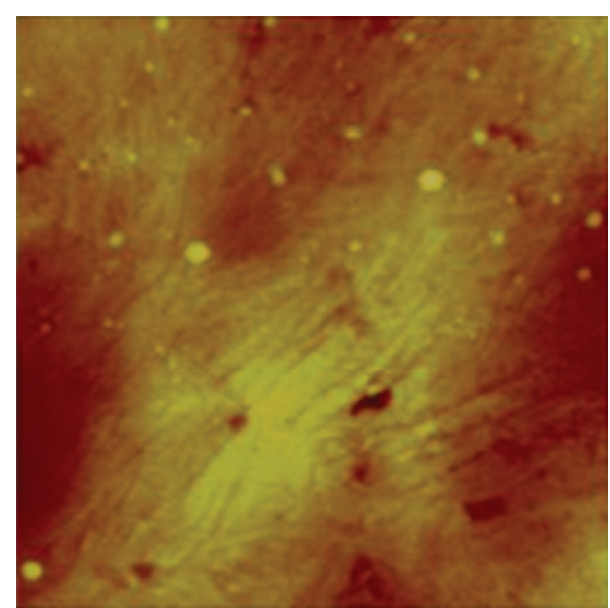

(a)

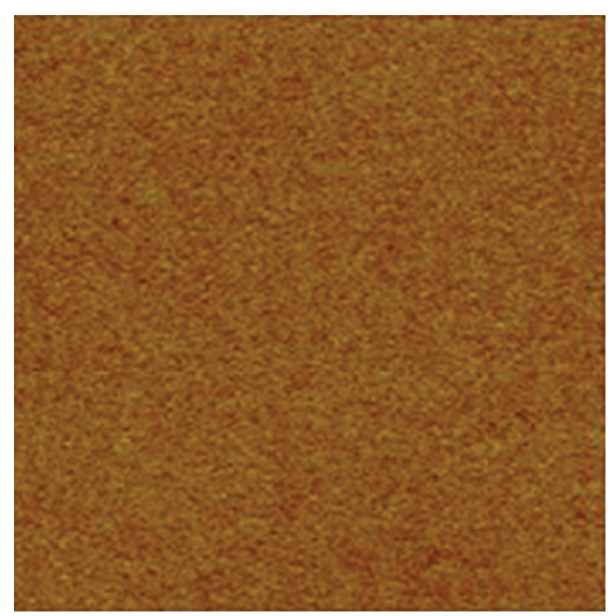

(c)

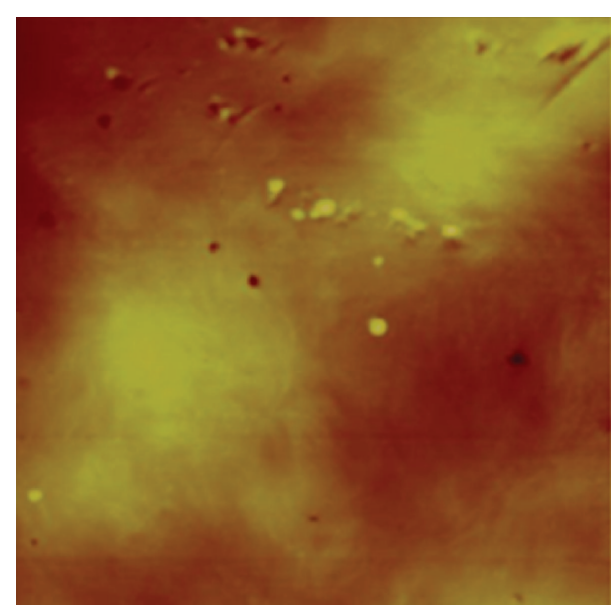

(b)

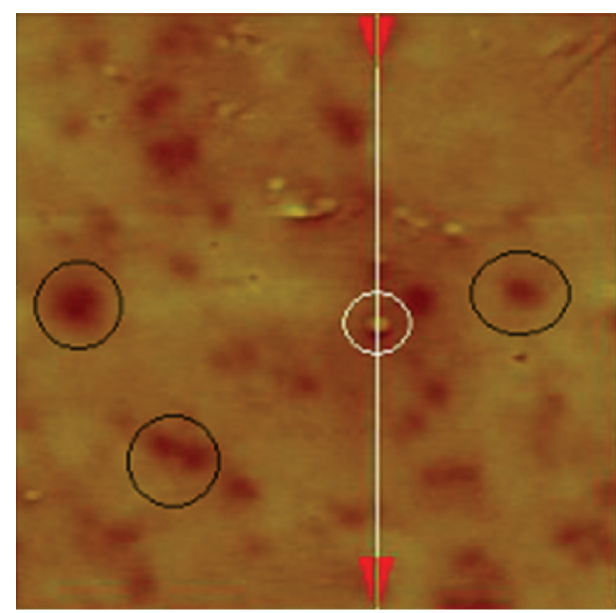

(d)

Figure 3: (a) AFM height image of MgO/LDPE material $(5 \mu \mathrm{m} \times 5 \mu \mathrm{m})$, (b) AFM height image of $\mathrm{SiO}_{2} / \mathrm{LDPE}$ material $(5 \mu \mathrm{m} \times 5 \mu \mathrm{m})$, (c) AFM lift mode phase image of MgO/LDPE in the same zone, and (d) AFM lift mode phase image of $\mathrm{SiO}_{2} / \mathrm{LDPE}$ in the same zone (after Zheng et al. [13]).

decrease in conductivity of the nanocomposites is derived from the decrease in mobility. Based on Lewis's interface charge model, the scattering effects of interfacial charge on the carrier migration may decrease the carriers' free path, also decreasing the carrier mobility.

As discussed above, the interface charge layer exists in $\mathrm{SiO}_{2} / \mathrm{LDPE}$, but not in MgO/LDPE. From Figure 4, we can see that the conductivity of $\mathrm{SiO}_{2} / \mathrm{LDPE}$ is slightly lower than that of $\mathrm{MgO} / \mathrm{LDPE}$, which implies that the interface charge led to a decrease in the conductivity. However, the conductivity of $\mathrm{MgO} / \mathrm{LDPE}$ is still lower than that of LDPE by about an order of magnitude, which means that the interface charge is not the dominant factor affecting the decrease in conductivity. The increase in trap density in $\mathrm{MgO} / \mathrm{LDPE}$ and $\mathrm{SiO}_{2} / \mathrm{LDPE}$ nanocomposites may be the key factor affecting the decrease in conductivity.

3.4. Space Charge Property. Figure 5(a) shows the space charge distribution of LDPE at $0.5 \mathrm{~min}$ and $10 \mathrm{~min}$, after the field application of $40 \mathrm{kV} / \mathrm{mm}$. After $0.5 \mathrm{~min}$ of field application, a positive space charge packet is injected from the anode into LDPE, where it moves towards the cathode side as polarization time increases. At the cathode side, after $0.5 \mathrm{~min}$ of field application, there is no obvious space charge accumulation. Ten minutes after the field application, a negative space charge is injected from the cathode. The maximum density of the positive space charge was approximately $10 \mathrm{C} / \mathrm{m}^{-3}$ and that for the negative space charge was approximately $8 \mathrm{C} / \mathrm{m}^{-3}$.

As shown in Figure 5(b), for $2 \mathrm{wt} \% \mathrm{MgO} / \mathrm{LDPE}$, after $0.5 \mathrm{~min}$ of field application, there is no obvious space charge accumulation in the bulk of the sample. After $10 \mathrm{~min}$ of field application, some positive charge is injected from the anode, but the density and amount of space charge are significantly less than those for pure LDPE. As shown in Figure 5(c), for $3 \mathrm{wt} \% \mathrm{MgO} / \mathrm{LDPE}$, no obvious space charge accumulation can be discerned during the experiment.

The space charge properties of $\mathrm{SiO}_{2} / \mathrm{LDPE}$ are shown in Figures $5(\mathrm{~d})$ and $5(\mathrm{e})$. For $2 \mathrm{wt} \% \mathrm{SiO}_{2} / \mathrm{LDPE}$, after $0.5 \mathrm{~min}$ 


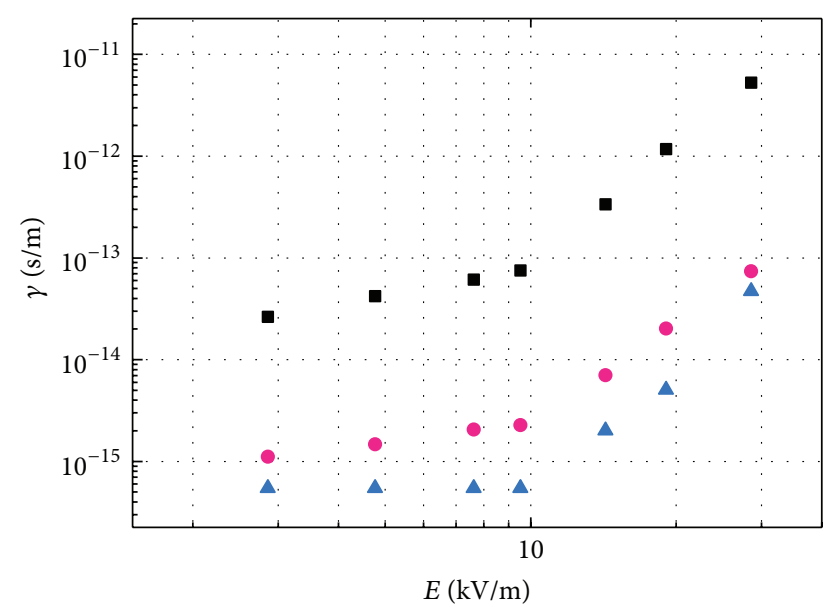

- LDPE

- $3 \% \mathrm{MgO} / \mathrm{LDPE}$

- $3 \% \mathrm{SiO}_{2} / \mathrm{LDPE}$

FIGURE 4: Conductivity versus electric field characteristics of three kinds of materials at $70^{\circ} \mathrm{C}$.

TABLE 1: Weibull data for the DC breakdown strength of MgO/LDPE and $\mathrm{SiO}_{2} / \mathrm{LDPE}$ with various loadings.

\begin{tabular}{lc}
\hline Samples & $\begin{array}{c}\text { Scale parameter } \\
(\mathrm{kV} / \mathrm{mm})\end{array}$ \\
\hline $\mathrm{LDPE}$ & 287.2 \\
$2 \% \mathrm{MgO} / \mathrm{LDPE}$ & 315.4 \\
$3 \% \mathrm{MgO} / \mathrm{LDPE}$ & 331.1 \\
$2 \% \mathrm{SiO}_{2} / \mathrm{LDPE}$ & 349.3 \\
$3 \% \mathrm{SiO}_{2} / \mathrm{LDPE}$ & 394.7 \\
\hline
\end{tabular}

of field application, there is no obvious space charge accumulation in the bulk of the sample. After $10 \mathrm{~min}$ of field application, a small positive charge is injected from the anode. The injection charge amount is less than that of $2 \mathrm{wt} \% \mathrm{MgO} / \mathrm{LDPE}$. From Figure 5(e), we can see that, for $3 \mathrm{wt} \% \mathrm{SiO}_{2} / \mathrm{LDPE}$, no space charge appeared during the experiment.

From the space charge experimental results, it is clear that space charge could be suppressed by the addition of $\mathrm{MgO}$ or $\mathrm{SiO}_{2}$ nanopowder. When the weights of $\mathrm{MgO}$ or $\mathrm{SiO}_{2}$ nanopowder were $2 \%$, there was less space charge in $\mathrm{SiO}_{2} /$ $\mathrm{LDPE}$ than in $\mathrm{MgO} / \mathrm{LDPE}$.

3.5. DC Breakdown. The Weibull probability plot for DC breakdown strength of LDPE and its nanocomposites at room temperature is shown in Figure 6, and the scale parameters are shown in Table 1. It can be observed from Table 1 that the nanocomposites can effectively improve the breakdown strength and $\mathrm{SiO}_{2} / \mathrm{LDPE}$ is better than $\mathrm{MgO} / \mathrm{LDPE}$ in that regard. The breakdown strength of $3 \mathrm{wt} \% \mathrm{SiO}_{2} / \mathrm{LDPE}$ can reach $394.7 \mathrm{kV} / \mathrm{mm}$, which is the largest among the five materials. Interface charge zones in the $\mathrm{SiO}_{2} / \mathrm{LDPE}$ nanocomposite, which lead to an increase in the carrier scattering probability, may be the reason for the increase in the breakdown strength of the $\mathrm{SiO}_{2} / \mathrm{LDPE}$ nanocomposite.

\section{Discussion}

Table 2 shows a summary of the DC dielectric properties for LDPE, as well as $\mathrm{MgO} / \mathrm{LDPE}$ and $\mathrm{SiO}_{2} / \mathrm{LDPE}$ nanocomposites. Comparing the DC dielectric properties of $\mathrm{MgO} / \mathrm{LDPE}$ and $\mathrm{SiO}_{2} / \mathrm{LDPE}$ nanocomposites, it can be seen that the $\mathrm{SiO}_{2} /$ LDPE nanocomposite has less DC conductivity, less space charge density, and larger breakdown strength. As discussed above, the interface charge layer has a positive effect on the dielectric properties. The $\mathrm{SiO}_{2} / \mathrm{LDPE}$ nanocomposite, with an interface charge layer, has better dielectric performance compared with $\mathrm{MgO} / \mathrm{LDPE}$, in which no interface charge was found, which supports the view proposed above.

Although there is no obvious interface charge layer detected in the $\mathrm{MgO} / \mathrm{LDPE}$ nanocomposite, the dielectric properties of $\mathrm{MgO} / \mathrm{LDPE}$ were still significantly improved compared with LDPE, as shown in Table 2. It is possible that the interface charge is not the dominant factor affecting the dielectric properties of the nanocomposites.

Many researchers have reported the trap density and depth of $\mathrm{MgO} / \mathrm{LDPE}$ and $\mathrm{SiO}_{2} / \mathrm{LDPE}$ nanocomposites using the thermally stimulated current (TSC) method [16, 17]. As shown in Tables 3 and 4, the peak value of TSC for $\mathrm{MgO} / \mathrm{LDPE}$ nanocomposites increases with the increment of $\mathrm{MgO}$ nanoparticle loading and the peak position of TSC shifts to low temperature region. Although the TSC peak current of $\mathrm{SiO}_{2} / \mathrm{LDPE}$ nanocomposites decreases, the current peak is widened. It is also found that the TSC value tested by Yin is obviously larger than that tested by Peng. The reason is that the polarization electric field of the two researchers' TSC test is different; polarization electric field of Yin's test is about 50 times larger than that of Peng's test leading to a larger current value. The TSC curve of LDPE in the temperature region of $230 \mathrm{~K}-380 \mathrm{~K}$ usually characterizes the heat release process of the trapped carriers. Because the heating rate of each test is the same, the area of TSC peak can demonstrate the number of trapped carriers which are also called as space charge and this space charge should be detected by PEA test. From Tables 3 and 4, it is found that the area of TSC peak for $\mathrm{LDPE}$ is lower than that of $\mathrm{MgO} / \mathrm{LDPE}$ (any loading weights) and $\mathrm{SiO}_{2} / \mathrm{LDPE}$ (loading weights above 3\%) nanocomposite. If so, it led to this question: TSC measurement results demonstrated that nanocomposite should have more space charge than LDPE, but why is there no space charge detected in $\mathrm{MgO} / \mathrm{LDPE}$ and $\mathrm{SiO}_{2} / \mathrm{LDPE}$ nanocomposite by PEA? So it is concluded that the TSC peak of nanocomposite does not characterize the heat release process of the trapped carriers and there may be other mechanisms.

Considering that the surface of nanoparticles may carry a large number of polar groups, we tested nano-MgO and nano- $\mathrm{SiO}_{2}$ powders by Fourier Transform Infrared spectroscopy. It can be seen from Figure 7 that a large number of hydroxyl groups were detected in nano- $\mathrm{MgO}$ and nano$\mathrm{SiO}_{2}$ powders. The conformation of polyethylene molecular chain may interact with hydroxyl groups by hydrogen bond, thus forming a polar interface dipole layer in the $\mathrm{MgO} / \mathrm{LDPE}$ 


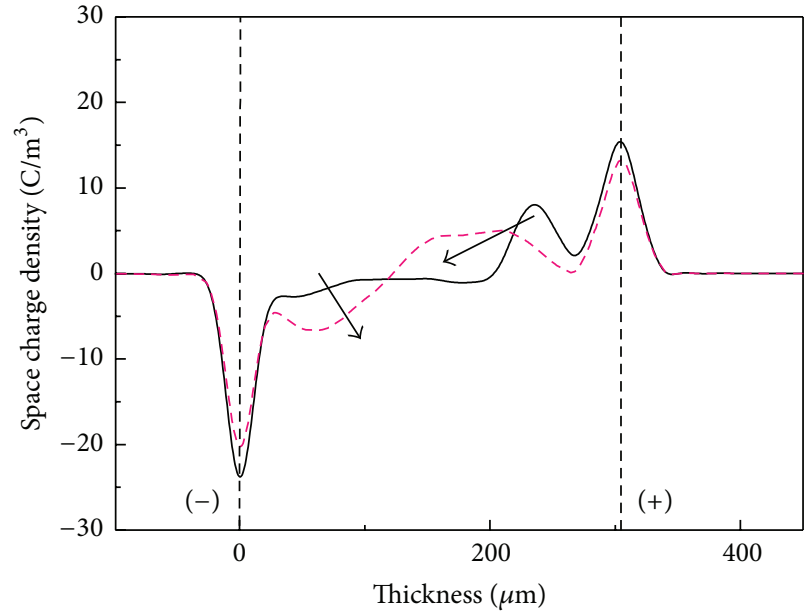

$-40 \mathrm{kV} / \mathrm{mm} 0.5 \mathrm{~min}$

(a)

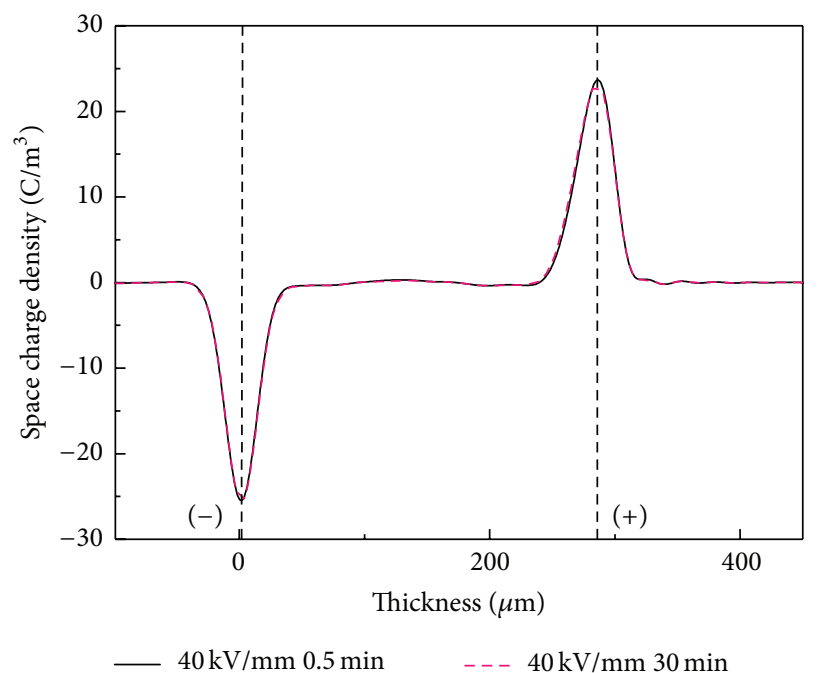

(c)

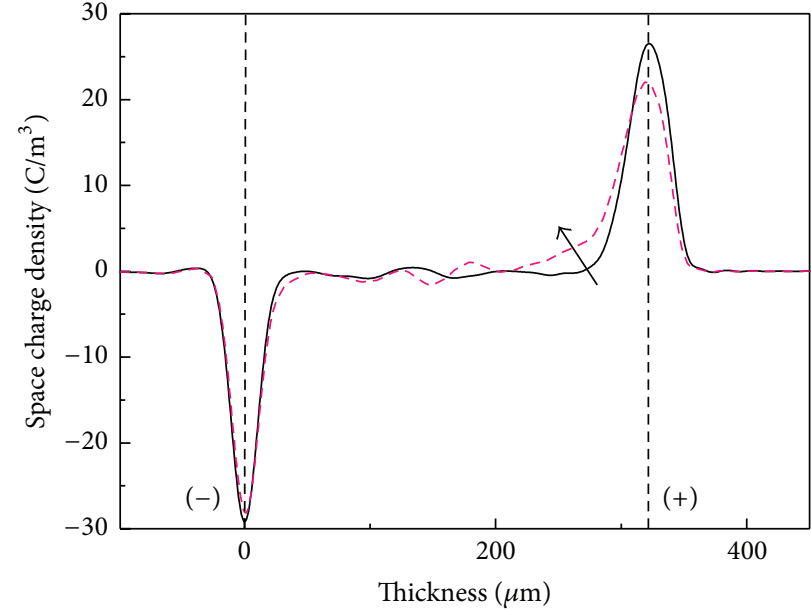

— $40 \mathrm{kV} / \mathrm{mm} 0.5 \mathrm{~min} \quad$ - - $40 \mathrm{kV} / \mathrm{mm} 30 \mathrm{~min}$

(b)

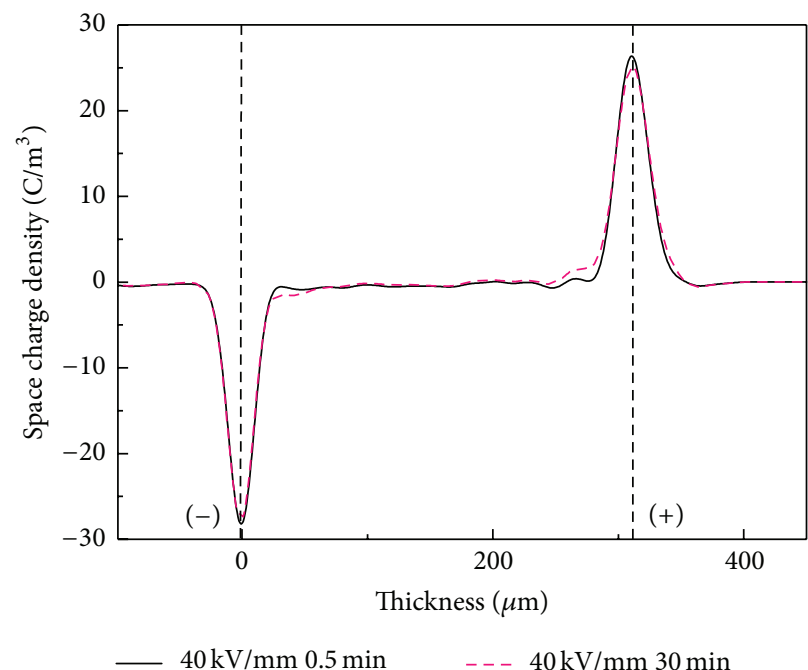

(d)

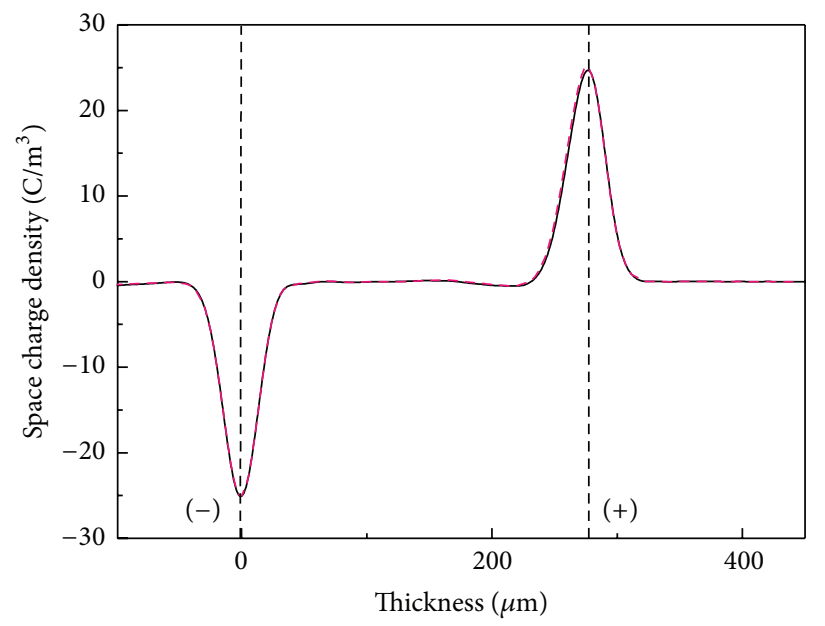

_ $40 \mathrm{kV} / \mathrm{mm} 0.5 \mathrm{~min} \quad \ldots-{ }_{-} 40 \mathrm{kV} / \mathrm{mm} 30 \mathrm{~min}$

(e)

Figure 5: Space charge properties of (a) LDPE, (b) $2 \mathrm{wt} \% \mathrm{MgO} / \mathrm{LDPE}$, (c) $3 \mathrm{wt} \% \mathrm{MgO} / \mathrm{LDPE}$, (d) $2 \mathrm{wt} \% \mathrm{SiO} / 2 \mathrm{LDPE}$, and (e) $3 \mathrm{wt} \%$ $\mathrm{SiO}_{2} /$ LDPE. 
TABLE 2: Summary of DC dielectric properties of LDPE and nanocomposite.

\begin{tabular}{lccc}
\hline Materials & $\begin{array}{c}\text { DC conductivity }\left(70^{\circ} \mathrm{C},\right. \\
30 \mathrm{kV} / \mathrm{mm}, 3 \mathrm{wt} \%)\end{array}$ & $\begin{array}{c}\text { Space charge }\left(30^{\circ} \mathrm{C},\right. \\
40 \mathrm{kV} / \mathrm{mm}, 2 \mathrm{wt} \%)\end{array}$ & Breakdown strength $\left(30^{\circ} \mathrm{C}, 3 \mathrm{wt} \%\right)$ \\
\hline $\mathrm{LDPE}$ & $5 \times 10^{-12} \mathrm{~S} / \mathrm{m}$ & $10 \mathrm{C} / \mathrm{m}^{3}$ & $287 \mathrm{kV} / \mathrm{mm}$ \\
$\mathrm{MgO} / \mathrm{LDPE}$ & $4 \times 10^{-14} \mathrm{~S} / \mathrm{m}$ & $3 \mathrm{C} / \mathrm{m}^{3}$ & $331 \mathrm{kV} / \mathrm{mm}$ \\
$\mathrm{SiO}_{2} / \mathrm{LDPE}$ & $1.5 \times 10^{-14} \mathrm{~S} / \mathrm{m}$ & $1 \mathrm{C} / \mathrm{m}^{3}$ & $394 \mathrm{kV} / \mathrm{mm}$ \\
\hline
\end{tabular}

TABLE 3: Summary of TSC test results of LDPE and MgO/LDPE nanocomposite (Table 3 was created by authors from data in Peng et al. [16]).

\begin{tabular}{lccc}
\hline Materials & $\begin{array}{c}\text { Peak } \\
\text { current } \\
\text { value }\end{array}$ & $\begin{array}{c}\text { Peak } \\
\text { position }\end{array}$ & $\begin{array}{c}\text { Area of TSC } \\
\text { peak compared } \\
\text { with LDPE }\end{array}$ \\
\hline LDPE & $0.6 \mathrm{pA}$ & $350 \mathrm{~K}$ & - \\
$0.1 \% \mathrm{MgO} / \mathrm{LDPE}$ & $0.7 \mathrm{pA}$ & $337 \mathrm{~K}$ & Increased \\
$0.5 \% \mathrm{MgO} / \mathrm{LDPE}$ & $0.75 \mathrm{pA}$ & $320 \mathrm{~K}$ & Increased \\
$1 \% \mathrm{MgO} / \mathrm{LDPE}$ & $0.9 \mathrm{pA}$ & $305 \mathrm{~K}$ & Increased \\
$2 \% \mathrm{MgO} / \mathrm{LDPE}$ & $1.08 \mathrm{pA}$ & $300 \mathrm{~K}$ & Increased \\
$5 \% \mathrm{MgO} / \mathrm{LDPE}$ & $1.5 \mathrm{pA}$ & $280 \mathrm{~K}$ & Increased \\
\hline
\end{tabular}

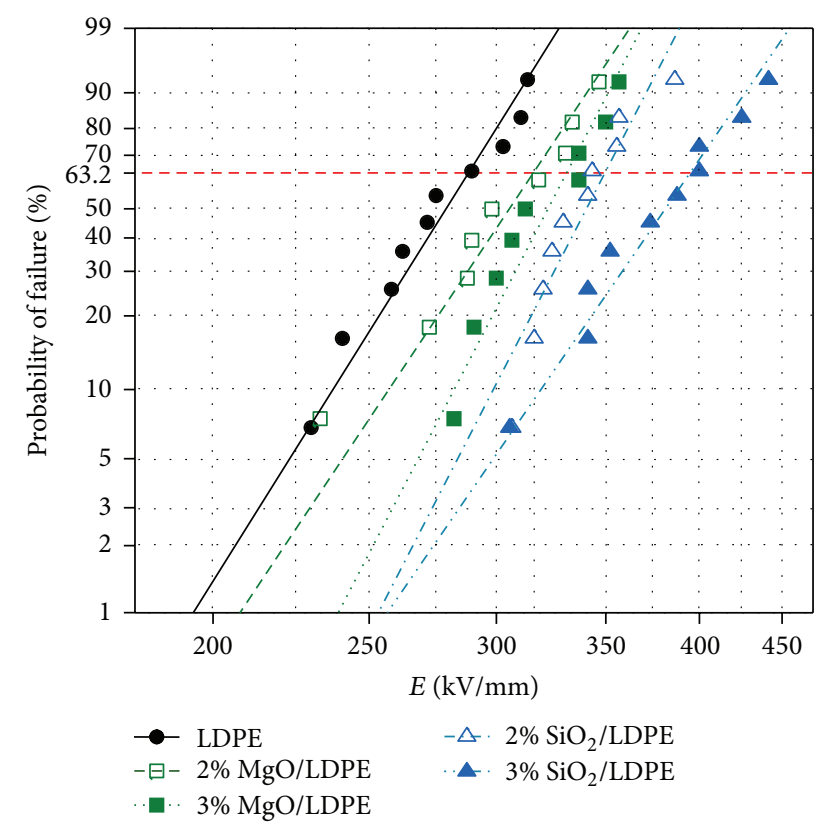

FIgURE 6: Weibull plots of the DC breakdown strength of $\mathrm{MgO} / \mathrm{LDPE}$ and $\mathrm{SiO}_{2}$ /LDPE with various loadings.

and $\mathrm{SiO}_{2} / \mathrm{LDPE}$ nanocomposite. As shown in Figure 8(a), when the electric field is zero, all of these electric dipoles are randomly oriented so the macrodipole moment of the interface dipole layer is equal to zero. When nanocomposite was applied to electric fields, as shown in Figure 8(b), the dipoles align along the same direction as the field resulting in a macrodipole moment in the interface layer. It is supposed that the TSC peak of nanocomposite does not characterize the heat release process of the trapped carriers but the depolarization process of interface dipole layer. As the loading of
TABLE 4: Summary of TSC test results of LDPE and $\mathrm{SiO}_{2} / \mathrm{LDPE}$ nanocomposite (Table 4 was created by authors from data in Yin et al. [17]).

\begin{tabular}{|c|c|c|c|}
\hline Materials & $\begin{array}{c}\text { Peak } \\
\text { current } \\
\text { value }\end{array}$ & $\begin{array}{c}\text { Peak } \\
\text { position }\end{array}$ & $\begin{array}{c}\text { Area of TSC } \\
\text { peak compared } \\
\text { with LDPE }\end{array}$ \\
\hline LDPE & $26 \mathrm{pA}$ & $320 \mathrm{~K}$ & - \\
\hline $1 \% \mathrm{SiO}_{2} / \mathrm{LDPE}$ & $3 \mathrm{pA}$ & $290 \mathrm{~K}$ & Decreased \\
\hline $3 \% \mathrm{SiO}_{2} / \mathrm{LDPE}$ & $9.5 \mathrm{pA}$ & $278 \mathrm{~K}$ & Nearly equal \\
\hline $5 \% \mathrm{SiO}_{2} / \mathrm{LDPE}$ & $21 \mathrm{pA}$ & $258 \mathrm{~K}$ & Increased \\
\hline
\end{tabular}

nanopowders increases, interface dipole moment increases, and then the area of TSC peak also increases as shown in Tables 3 and 4. From what has been discussed above, a hypothesis of interface dipole layer was proposed to explain the experiments results in nanocomposite. Under the electric field, the interface dipole layer showed macrodipole moment to make the polarity of interface layer stronger. Carriers free paths were then reduced by the scattering effect of interface dipole layer so that dielectric properties of nanocomposite are improved.

In addition, dielectric properties of polymer are closely related to the crystalline structure. To understand the change of crystallinity of nanocomposite, $\mathrm{MgO} / \mathrm{LDPE}$ and $\mathrm{SiO}_{2} / \mathrm{LDPE}$ nanocomposite films were tested by XRD. As shown in Figure 9, two typical sharp diffraction peaks representing (110) and (200) crystal plane of LDPE appear at $21.4^{\circ}$ and $23.8^{\circ}$. After adding nano- $\mathrm{MgO}$ or nano- $\mathrm{SiO}_{2}$ powders to LDPE, it is found that the diffraction peak intensity of (110) and (200) crystal plane increased which indicated that the crystallinity of nanocomposite is increased. It is supposed that the nanoparticles played a role of nucleating agent to promote the crystallization and increase the packing density of polyethylene molecular chains. An increment of crystallization means a decrease of amorphous region. According to the classical dielectric theory, the free volume that exists in the amorphous region will be the favorable place where electron acceleration and ion migration happened, leading to the decrease of dielectric properties [18]. Therefore, the reduction of free volume is another reason for the improvement of nanocomposite.

\section{Conclusions}

We detected the interface charge layer in $\mathrm{SiO}_{2} / \mathrm{LDPE}$ and $\mathrm{MgO} / \mathrm{LDPE}$ nanocomposites using the Porod curve obtained from SAXS measurements. The Porod curve of some $\mathrm{SiO}_{2} / \mathrm{LDPE}$ nanocomposites showed negative divergence, but 


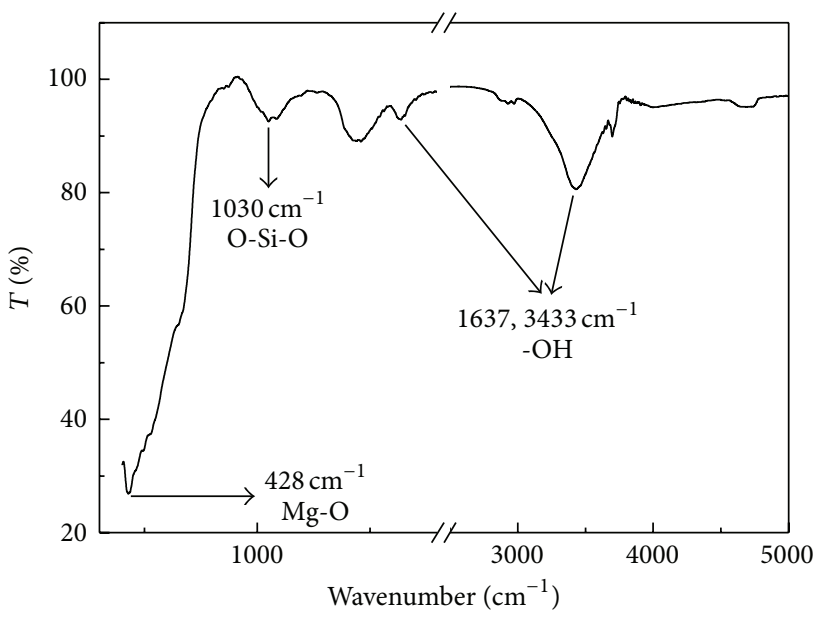

(a) $\mathrm{MgO}$ powder

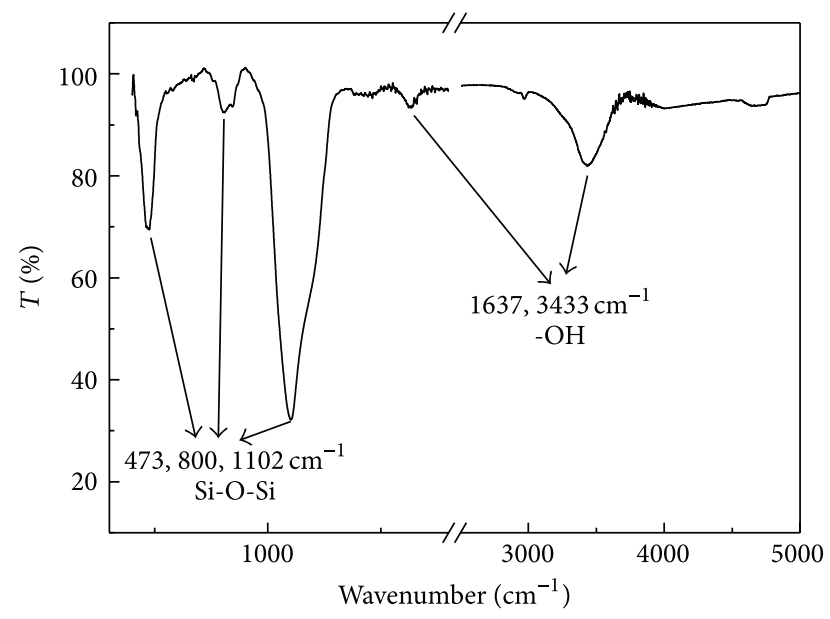

(b) $\mathrm{SiO}_{2}$ powder

FIGURE 7: The FTIR spectra of (a) nano-MgO powders and (b) nano- $\mathrm{SiO}_{2}$ powders.

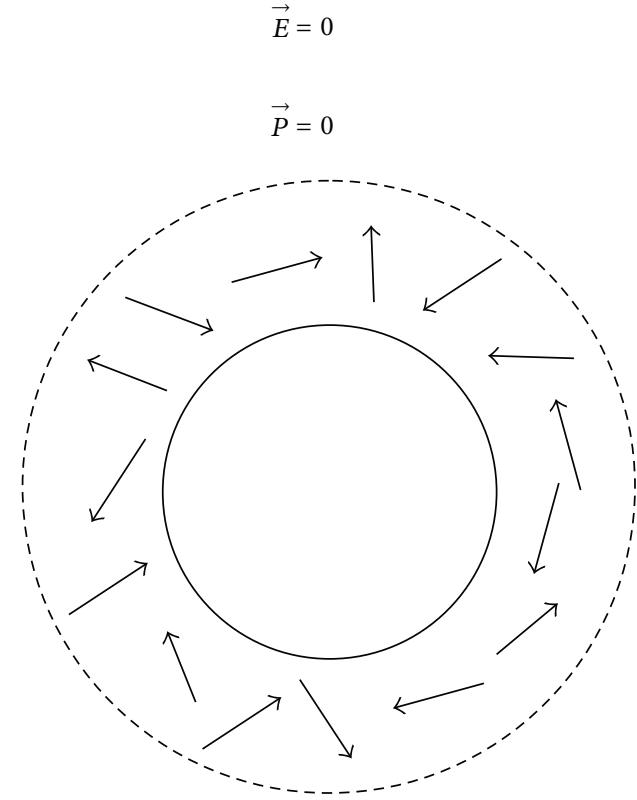

(a) Interface dipole layer situation: when the electric field is zero, the macro dipole moment of interface dipole layer is also zero

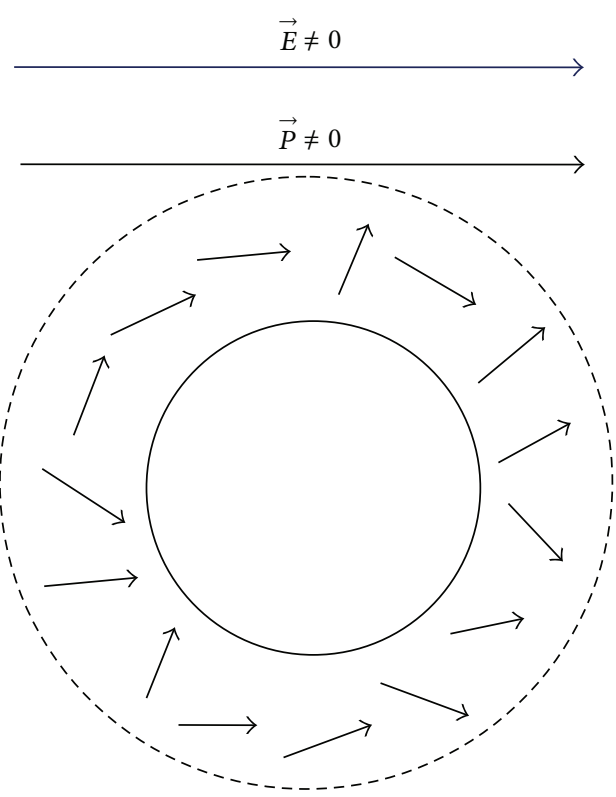

(b) Interface dipole layer situation: when the electric field is not zero, a strong interface dipole layer was induced

FIGURE 8: Interface dipole layer situation (a) without electric field and (b) with electric field.

the LDPE and MgO/LDPE did not, which revealed that interfacial charge may exist in the $\mathrm{SiO}_{2} / \mathrm{LDPE}$ nanocomposite, based on Porod's law. The $\mathrm{SiO}_{2}$ /LDPE nanocomposite, with an interface charge layer, has better dielectric performance than $\mathrm{MgO} / \mathrm{LDPE}$, suggesting that the interface charge layer has a positive effect on the dielectric properties. Although there is no obvious interface charge layer detected in the $\mathrm{MgO} / \mathrm{LDPE}$ nanocomposite, the dielectric properties of $\mathrm{MgO} / \mathrm{LDPE}$ still significantly improved, which revealed that the interface charge is not the dominant factor influencing the dielectric properties. Based on the experiments results and discussion, we proposed two universal influence factors on the dielectric properties of $\mathrm{MgO} / \mathrm{LDPE}$ and $\mathrm{SiO}_{2} / \mathrm{LDPE}$ nanocomposite. First, the area of TSC peak of nanocomposite was larger than that of LDPE but no space charge was detected in nanocomposite which revealed that TSC peak of nanocomposite does not characterize the heat release process of the trapped carriers but the depolarization process of interface dipole layer. Under the electric field, the interface dipole layer showed macrodipole moment to make the polarity of interface layer stronger. Carriers free path were then reduced by the scattering effect of interface dipole layer leading to an improvement of dielectric properties of nanocomposite. Second, XRD results indicated that the 


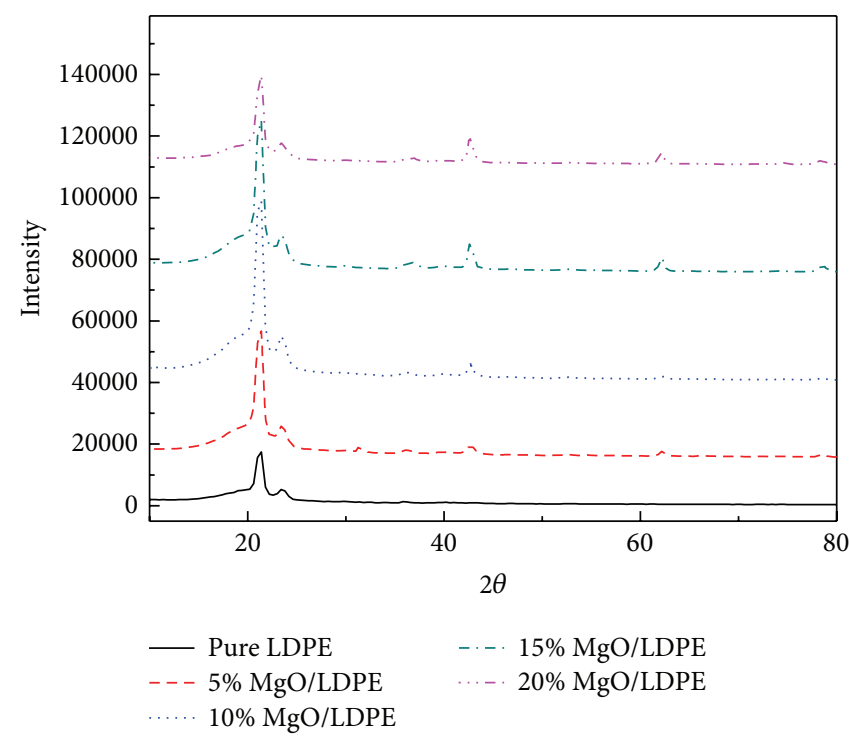

(a)

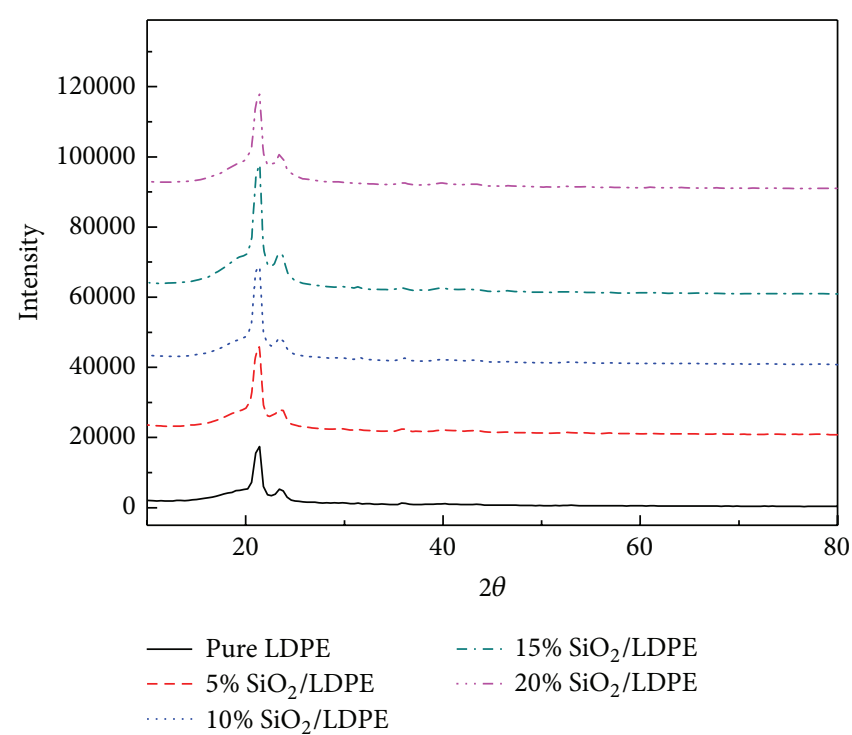

(b)

FIGURE 9: XRD pattern of (a) MgO/LDPE nanocomposite and (b) $\mathrm{SiO}_{2} / \mathrm{LDPE}$ nanocomposite.

crystallinity of nanocomposite is increased by the addition of nanoparticles which signify the reduction of free volume in the nanocomposite. The reduction of free volume will suppress electrons acceleration and ions migration then improving dielectric properties.

\section{Conflict of Interests}

The authors declare that there is no conflict of interests regarding the publication of this paper.

\section{Acknowledgments}

The authors wish to thank the National Science Foundation of China under Project no. 51337002 and the Key Laboratory of Engineering Dielectrics and Its Application Doctor Research Program and the Institute of High Energy Physics of the Chinese Academy of Sciences.

\section{References}

[1] T. Tanaka, A. Bulinski, and J. Castellon, "Dielectric properties of XLPE/Sio ${ }_{2}$ nanocomposites based on CIGRE WG D1.24 cooperative test results," IEEE Transactions on Dielectrics and Electrical Insulation, vol. 18, no. 5, pp. 1484-1517, 2011.

[2] Y. Jiaming, W. Xuan, H. Baozhong, H. Zhao, and M. Xu, "DC conductivity characteristic of LDPE nanocomposite and its effect on electric field distribution in HVDC cables," Proceedings of the CSEE, vol. 34, no. 9, pp. 1454-1461, 2014.

[3] J. Wu, Y. Yin, L. Lan, Q. Wang, X. Li, and D. Xiao, “The influence of nano-filler concentration on space charge behavior in LDPE/ silica nanocomposites," Proceeding of the CSEE, vol. 32, no. 28, pp. 177-183, 2012.

[4] H. Zhao, M. Xu, J. Yang, W. Zhang, X. Wang, and Q. Lei, "Space charge and electric treeing resistance properties of $\mathrm{MgO} / \mathrm{LDPE}$ nanocomposite," Proceedings of the CSEE, vol. 32, no. 16, pp. 196-202, 2012.
[5] K. Y. Lau, A. S. Vaughan, G. Chen, I. L. Hosier, A. F. Holt, and K. Y. Ching, "On the space charge and DC breakdown behavior of polyethylene/silica nanocomposites," IEEE Transactions on Dielectrics and Electrical Insulation, vol. 21, no. 1, pp. 340-351, 2014.

[6] Y. Murakami, M. Nemoto, S. Okuzumi et al., "DC conduction and electrical breakdown of MgO/LDPE nanocomposite," IEEE Transactions on Dielectrics and Electrical Insulation, vol. 15, no. 1, pp. 33-39, 2008.

[7] M. Roy, J. K. Nelson, R. K. MacCrone, and L. S. Schadler, "Candidate mechanisms controlling the electrical characteristics of silica/XLPE nanodielectrics," Journal of Materials Science, vol. 42, no. 11, pp. 3789-3799, 2007.

[8] T. J. Lewis, "Interfaces are the dominant feature of dielectrics at the nanometric level," IEEE Transactions on Dielectrics and Electrical Insulation, vol. 11, no. 5, pp. 739-753, 2004.

[9] T. Tanaka, M. Kozako, N. Fuse, and Y. Ohki, "Proposal of a multi-core model for polymer nanocomposite dielectrics," IEEE Transactions on Electrical Insulation, vol. 12, no. 4, pp. 669-681, 2005.

[10] Z. Yuping, Small Angle X-Ray Scattering-Theory, Testing, Calculation and Application, Chemical Industry Press, Beijing, China, 2008.

[11] X. Liu, J. Yin, and W. Cheng, "Research on interface and fractal characteristics of $\mathrm{PI} / \mathrm{Al}_{2} \mathrm{O}_{3}$ Films by SAXS," Acta Physica Sinica, vol. 60, no. 5, pp. 96-101, 2011.

[12] X. Yao, W. Dong, and S. Yuhan, "Dependence of silica sol properties on synthesis situation studied by SAXS," Acta Physica Sinica, vol. 54, no. 6, pp. 2814-2820, 2005.

[13] C. J. Zheng, W. L. Zhang, H. Zhao, X. Wang, Z. Sun, and J. Yang, "Assessment of nano dielectrics interface charge by electrokinetic sonic amplitude and atom force microscopy," IEEE Transactions on Dielectrics and Electrical Insulation, vol. 21, no. 4, pp. 1493-1500, 2014.

[14] H. Zhao, M. Guo, and B. Dong, "Determination of the transition-layer thickness of a crystalline polymer by using 
small-angle X-ray scattering," Acta Physica Sinica, vol. 53, no. 4, pp. 1247-1250, 2004.

[15] L. Zhihong, Z. Junping, W. Dong et al., "A positive deviation from Porod's law in SAXS of porous $\mathrm{ZrO}_{2}$ xerogels," Acta Chimica Sinica, vol. 58, no. 9, pp. 1147-1150, 2000.

[16] S. Peng, J. He, J. Hu, X. Huang, and P. Jiang, "Influence of functionalized $\mathrm{MgO}$ nanoparticles on electrical properties of polyethylene nanocomposites," IEEE Transactions on Dielectrics and Electrical Insulation, vol. 22, no. 3, pp. 1512-1519, 2015.

[17] Y. Yin, Z. Li, X. G. Li, and P. Jiang, "Thermally stimulated currents of $\mathrm{SiO}_{2}$ /low-density polyethylene micro- and nanocomposites," IEEJ Transactions on Electrical and Electronic Engineering, vol. 5, no. 4, pp. 385-390, 2010.

[18] M. Ieda, "Dielectric breakdown process of polymers," IEEE Transactions on Dielectrics and Electrical Insulation, vol. 15, no. 3, pp. 208-224, 1980. 

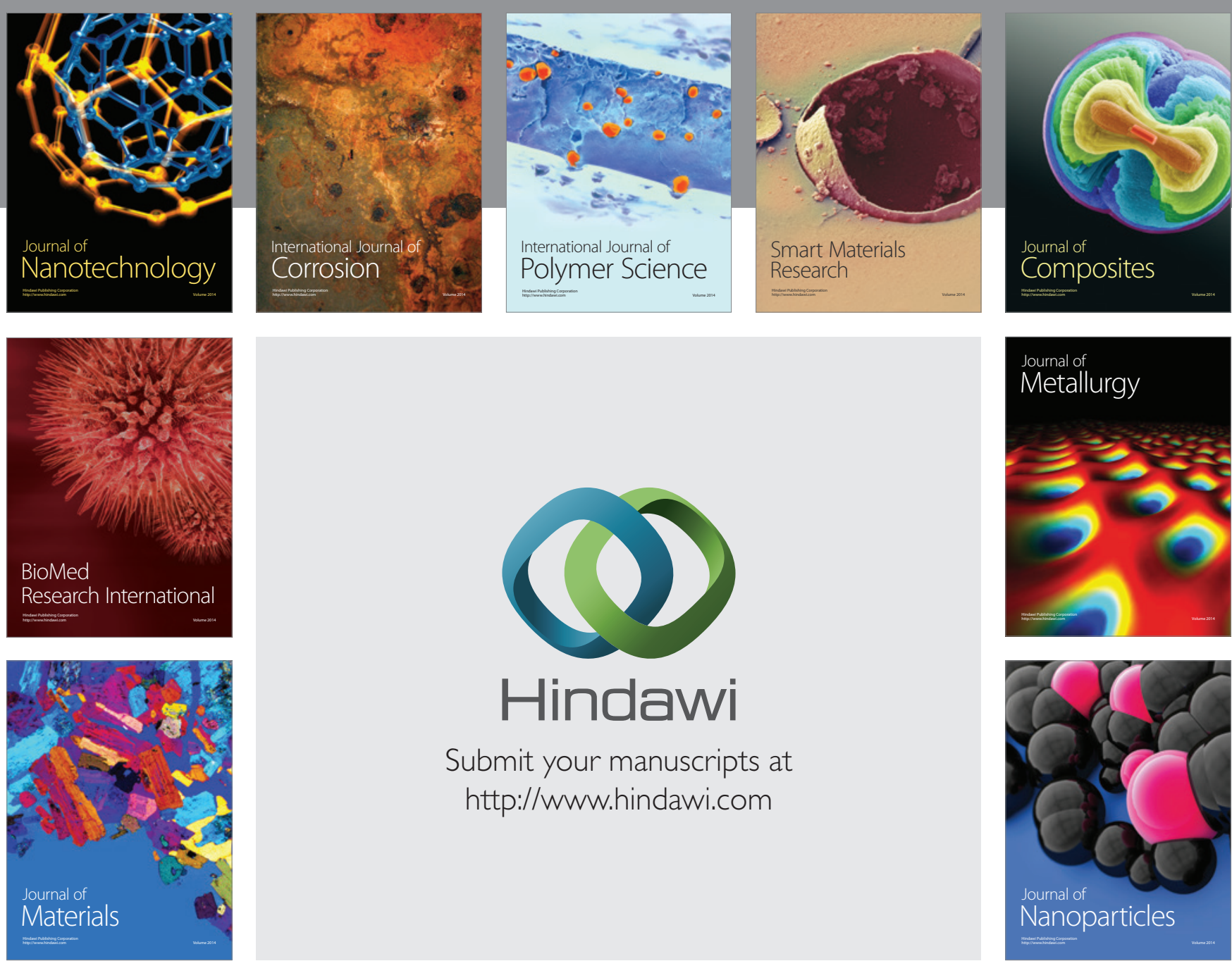

\section{Hindawi}

Submit your manuscripts at

http://www.hindawi.com

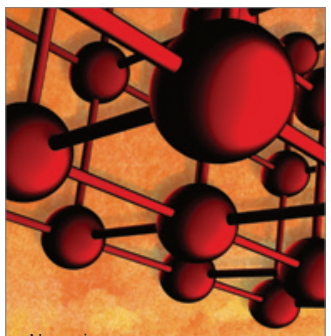

Materials Science and Engineering
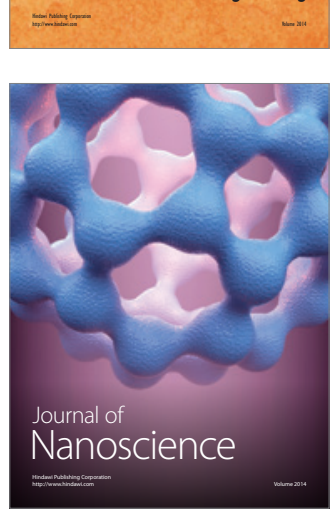
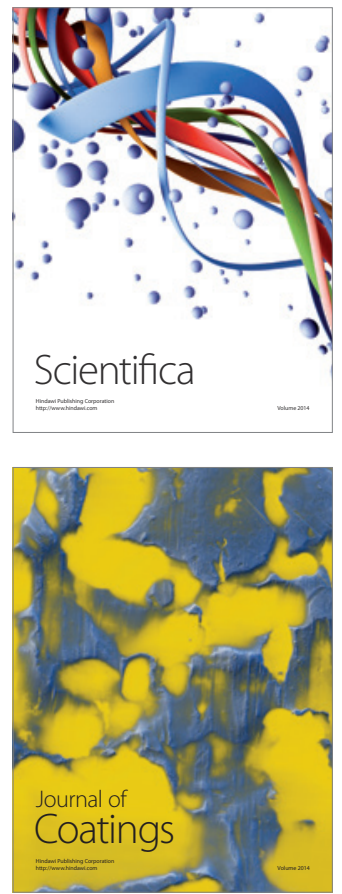
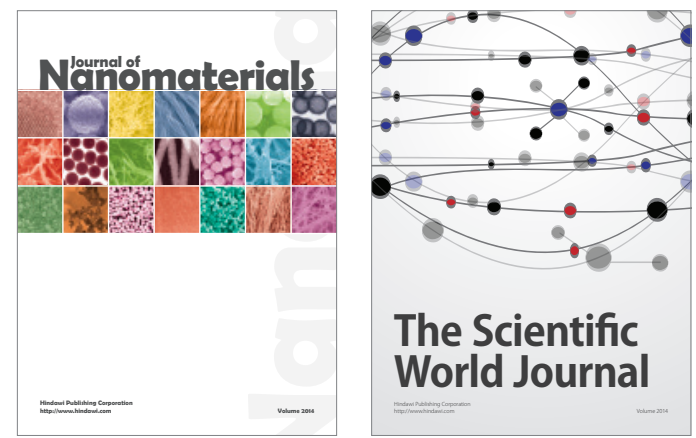

The Scientific World Journal
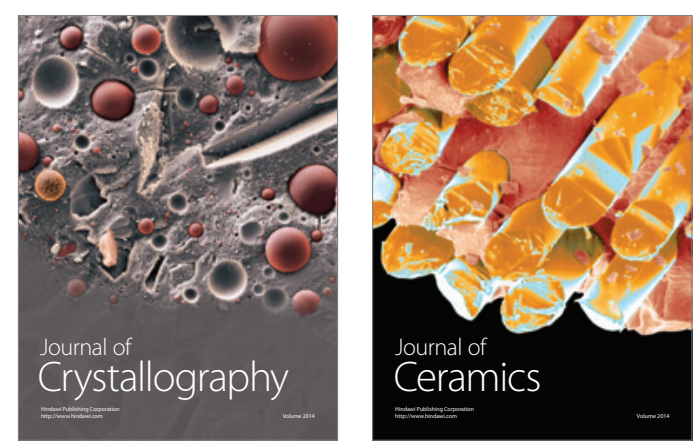
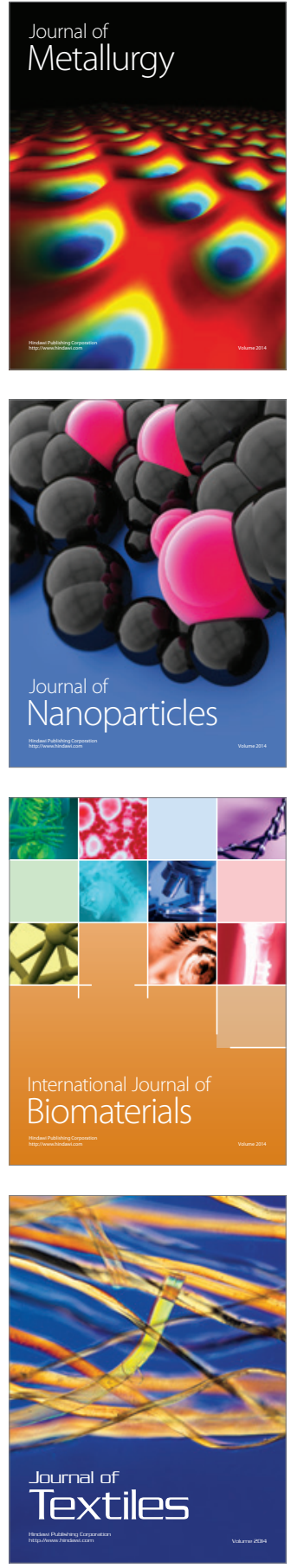